\title{
Comparison of three larviciding options for malaria vector control
}

S.D. Parvez ${ }^{1}$ and S.S. Al-Wahaibi ${ }^{1}$

$$
\begin{aligned}
& \text { المقارنة بين ثلاثة خيار ات مبيدة لليرقات لمكافحة نواقل الملاريا }
\end{aligned}
$$

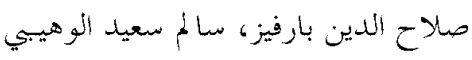

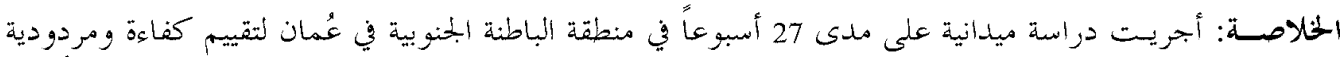

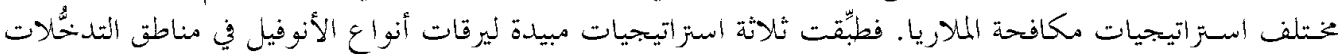

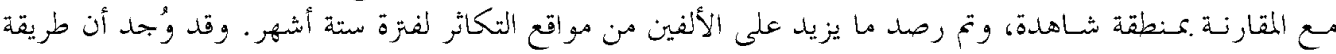

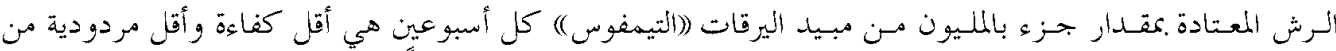

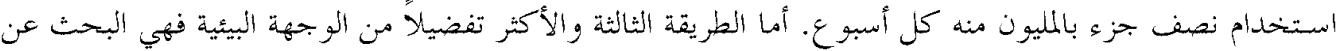

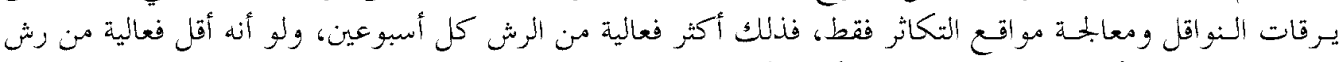

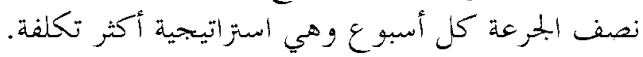

ABSTRACT A field study was carried out over 27 weeks in the south Batinah region of Oman to assess the efficiency and cost-effectiveness of different strategies for vector control of malaria. Three larviciding strategies for Anopheles spp. were applied to intervention areas and compared with a control area, with over 2000 breeding sites monitored for 6 months. The normal method of spraying $1 \mathrm{ppm}$ temephos larvicide fortnightly was found to be less efficient and less cost-effective than using $0.5 \mathrm{ppm}$ temephos applied weekly. A third, more environmentally favourable method, to search for vector larvae and treat only those breeding places, was more effective than fortnightly spraying but less effective than the weekly half dose and was the most expensive strategy.

Comparaison de trois options d'utilisation de larvicide pour la lutte contre les vecteurs du paludisme

RESUME Une étude sur le terrain a été réalisée pendant 27 semaines dans la région sud de Batinah à Oman afin d'évaluer l'efficacité et la rentabilité de différentes stratégies de lutte contre les vecteurs du paludisme. Trois stratégies d'utilisation de larvicides pour les espèces Anopheles ont été appliquées dans des zones d'intervention et comparées à une zone témoin, avec plus de 2000 gîtes larvaires surveillés pendant 6 mois. La méthode normale consistant à pulvériser 1 ppm du larvicide téméphos tous les quinze jours s'est avérée moins efficace et moins rentable qu'une application hebdomadaire de 0,5 ppm de téméphos. Une troisième méthode, plus favorable à l'environnement, consistant à chercher les larves des vecteurs et traiter uniquement les lieux de reproduction, était plus efficace que la pulvérisation tous les quinze jours mais moins efficace que la demi-dose hebdomadaire, et était la stratégie la plus coûteuse.

${ }^{1}$ Directorate of Environmental Health and Malaria Eradication, Ministry of Health, Muscat, Oman.

المجلة الصحية لشرق المتوسط، منظمة الصحة العالمية، المجلد التاسع، العدد ؟، ب... 


\section{Introduction}

In spite of over half a century of control efforts, the malaria situation at the beginning of the twenty-first century remains far from satisfactory, and is worsening. The UNICEF/WHO report of January 2000 revealed that 300-500 million cases of malaria occur annually in the world, leading to death for one-third of them [1]. As such, $40 \%$ of the world's population is under threat of this disease. Worst hit is Africa south of the Sahara, recording $90 \%$ of the world's malaria cases. Malaria is also a major public health problem in parts of Asia, the Middle East, Latin America, Eastern Europe and the Pacific. Malaria epidemics in India, Bangladesh, Pakistan and Sri Lanka are still common. The human cost of malaria is enormous in terms of health and social and economic costs. The economic loss from malaria was estimated at US\$ 2 billion in Africa alone in 1997 [1].

WHO has recognized malaria among the key health priorities of the world and has renewed efforts to combat this serious problem. On 30 October 1998, in collaboration with other agencies (UNICEF, United Nations Development Programme and the World Bank), WHO launched the Roll back malaria campaign in order to reduce the suffering due to malaria [2]. This bold drive has been initiated in the face of the serious constraints experienced by most malaria-endemic areas: financial problems, widespread drug resistance against commonly used antimalaria drugs, resistance of vectors to insecticides, population migration due to local disturbances or job-seeking, and climatic changes in favour of malaria transmission. New development projects such as dams and agricultural irrigation works create environmental changes more conducive to mosquito breeding and malaria transmission.
Currently, vector adulticiding and larviciding are the 2 major approaches used to control or eliminate malaria by attacking the vectors of the malaria parasite Anopheles spp. Larviciding-based malaria control/ eradication programmes are always costly, but in certain cases, e.g. vector exophily/ exophagy, manageable and well-defined vector-breeding sites and operational convenience, this approach is justified. Therefore, it is desirable to look for strategies that are innovative, cost-effective and have a low environmental impact.

This field study in Oman was carried out over 27 weeks, monitoring over 2000 breeding sites in the south Batinah region, to assess the efficiency and cost-effectiveness of different strategies for vector control of malaria.

\section{Methods}

\section{Study area}

Oman lies in an area where the Palaearctic, Ethiopian and Oriental zoogeographical regions overlap and is therefore a malaria zone with Mediterranean, African and Peninsular characteristics.

The country has 10 administrative regions, each divided into wilayat. At the wilayat level, malaria units are responsible for malaria eradication activities. The area under each unit is demarcated into sectors called darak for all operations. Centrally, the Directorate of Environmental Health and Malaria Eradication supervises the national programme. The study was carried out in 5 adjacent coastal sectors of the malaria-free wilayat of Barka in the south Batinah region. The area is part of a coastal belt with a hot and humid climate and a sandy landscape that is rich in date-palm farms.

In this region, wells 5-10 m deep, fitted with rigs and pumping machines provide

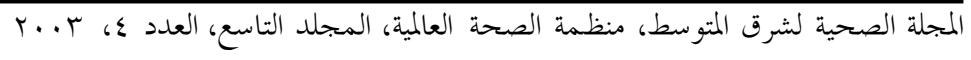


water in cemented irrigation tanks, measuring $3 \mathrm{~m}$ by $2 \mathrm{~m}$ by $0.5 \mathrm{~m}$ in depth, with smaller shallow $0.5 \mathrm{~m}$ by $0.5 \mathrm{~m}$ cemented structures attached. Tree plantations around these tanks provide shade to keep the water cool. Most of these tanks contain thick green algae and dead leaves from nearby trees. All these conditions make the tanks ideal places for mosquitoes to breed.

\section{Study design}

The usual larviciding procedure in the Oman national malaria eradication programme uses temephos 50\% EC [emulsifiable concentrate] applied weekly at $100 \mathrm{~g}$ active ingredient per hectare, i.e. 1 part per million (ppm). This is sprayed with Hudson $\mathrm{X}$-pert ${ }^{\circledR}$ pumps fitted with a cone jet nozzle. For this study the 5 sectors were treated as follows:

- Full dose fortnightly: 2 adjacent sectors were treated by 1 labourer every fortnight, 1 sector on alternate weeks, using the normal dose of $1 \mathrm{ppm}$ temephos.

- Half dose weekly: 1 sector was treated every week with the standard method, but using $0.5 \mathrm{ppm}$ temephos. One labourer treated 1 part every day to complete the whole sector (divided into 5 parts) in 5 days, and repeated this operation weekly for the whole study period.

- Treat only if positive: 1 sector was treated by a mobile team of 2 labourers. They carried out thorough larval checking on this sector (1 part everyday) and treated only those places containing anopheline larvae with 1 ppm temephos.

- Control: 1 sector was left without treatment as a control area to observe natural trends and compare the 3 treatment strategies.

\section{Evaluation}

The study was carried out from June 2001 to January 2002. The pre-intervention (baseline evaluation) phase was 1 June to 30 June and the intervention (treatment and evaluation) phase was 1 July to 30 December 2001 with the final evaluation on 13 January 2002.

We used the standard entomological criterion for a malaria eradication programme based on larviciding: to achieve and maintain a ‘quasi-zero' level of vector larvae [3].

A team consisting of a senior entomologist, 2 assistant inspectors from headquarters and 1 sanitary inspector or assistant sanitary inspector visited each area once a week to conduct larval cross-checking to assess the impact of 3 strategies of larviciding. During each visit, part of the control area was also surveyed. Larval samples collected by each team were daily sent to the Central Entomology Laboratories, where they were processes by the senior entomologist (principal investigator) for microscopic species identification, stage gradation, counting and susceptibility tests.

Previous records [5] and the baseline data in the study area revealed that Anopheles culicifacies and An. stephensi were the only anopheline species present in the area. In the pre-intervention period, the susceptibility to temephos of both vectors $A n$. culicifacies and An. stephensi was checked in each sector using the kit and method recommended by WHO [4]. Tests were repeated later whenever and wherever larval density permitted.

Seeb weather station was used as a proxy for the study area to collect climate data for the study period: mean temperature, humidity and rainfall. $\mathrm{pH}$ values were assessed in each area using pool and spa test kits.

المجلة الصحية لشرق المتوسط، منظمة الصحة العالمية، المجلد التاسع، العدد ع، ب... 


\section{Data analysis}

The data was collected in the field using a routine pro forma and was entered into EpiData, version 2.1 at the Directorate of Environmental Health and Malaria Eradication. Data was transferred to Stata version 6 statistical package for analysis. For quality control assurance of the data collection, the data was cross-validated by the senior entomologist in the Directorate through weekly field visits to the project site to take random measurements. Two researchers entered the data into EpiData.

The odds ratios for the 3 strategies were calculated, with 'positive signs of breeding places for Anopheles species' as the outcome variable. The explanatory variables were: half dose of normal weekly application of temephos, full-dose fortnightly; treat only if positive, no intervention, $\mathrm{pH}$ of the water, mean temperature. The attributable risk fraction was calculated, i.e. the amount of larvae breeding increased or decreased by each variable. The costs of the 3 strategies and the cost-benefit ratios were also calculated. The weekly data was combined into 2-week periods for graphical presentation.

\section{Results}

Vector density in the pre-intervention period ranged from 10.1 to 24.9 larvae per 100 dips for An. culicifacies and 0.4 to 7.0 for An. stephensi (Table 1). Around $91 \%$ of the total vector breeding occurred in tanks (Table 1 ); the remainder, around $3 \%$ and $6 \%$ respectively, occurred in wells and swamps.

Nearly $20 \%$ of breeding sites were larva positive 1 or more times when surveyed: $65 / 346$ of tanks in the control sector (27 surveys) and 81/427 in the 'treat only if positive' sector (54 surveys). Around half of larva-positive sites (37/65 of control sites and 40/81 of the 'treat positive' sites) were repeatedly found to be positive, on 210 occasions surveyed.

Figures 1-4 show the vector densities in the control and intervention sectors from June to December 2001 at fortnightly intervals. The control sector with no intervention showed a high level of vector breeding (between 20-50 larvae/100 dips) from August to December with a peak in September (Figure 1). In the sector treated with halfdose temephos weekly the vector density

\begin{tabular}{|c|c|c|c|c|c|}
\hline \multirow{2}{*}{$\begin{array}{l}\text { Intervention } \\
\text { sectors }\end{array}$} & \multicolumn{3}{|c|}{ Larva-positive sites } & \multicolumn{2}{|c|}{ Vector density (larvae/100 dips) } \\
\hline & $\begin{array}{c}\text { Total } \\
\text { No. }\end{array}$ & $\begin{array}{l}\text { In tar } \\
\text { No. }\end{array}$ & & $\begin{array}{c}\text { An. } \\
\text { culicifacies }\end{array}$ & $\begin{array}{l}\text { An. } \\
\text { stephensi }\end{array}$ \\
\hline Full-dose fortnightly & 37 & 33 & 89.2 & 17.0 & 0.6 \\
\hline Half-dose weekly & 19 & 17 & 89.4 & 24.9 & 5.3 \\
\hline Treat only if positive & 25 & 23 & 92.2 & 14.9 & 7.0 \\
\hline Control & 15 & 14 & 93.3 & 10.1 & 0.4 \\
\hline Total & 96 & 87 & 90.6 & & \\
\hline
\end{tabular}

المجلة الصحية لشرق المتوسط، منظمة الصحة العالمية، المجلد التاسع، العدد ع، ب... 


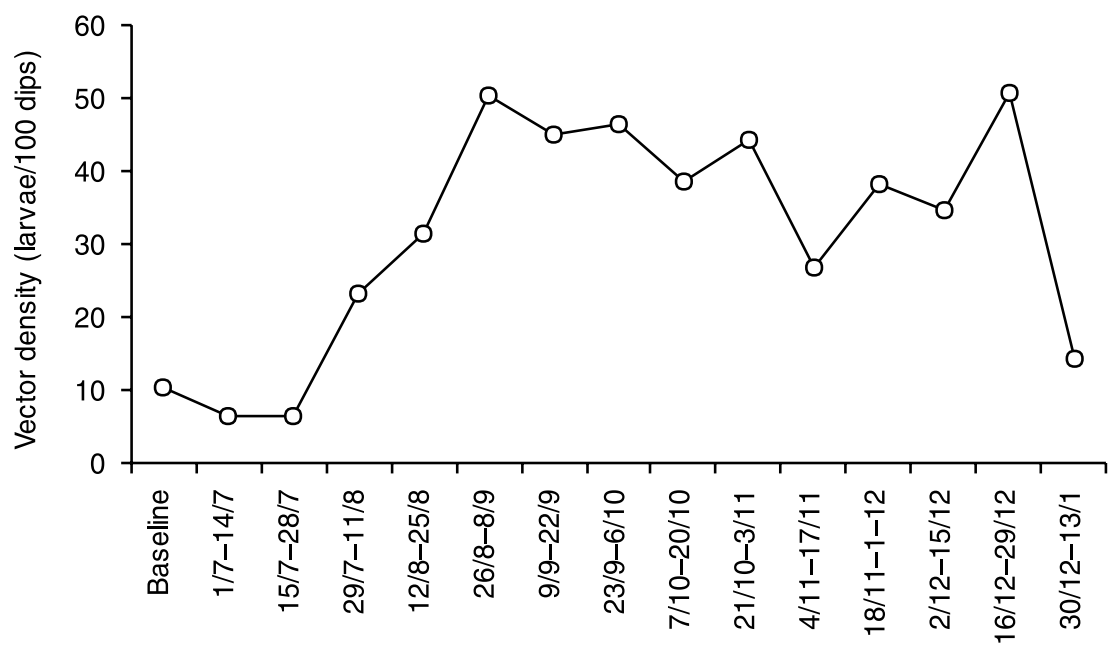

Fortnightly periods

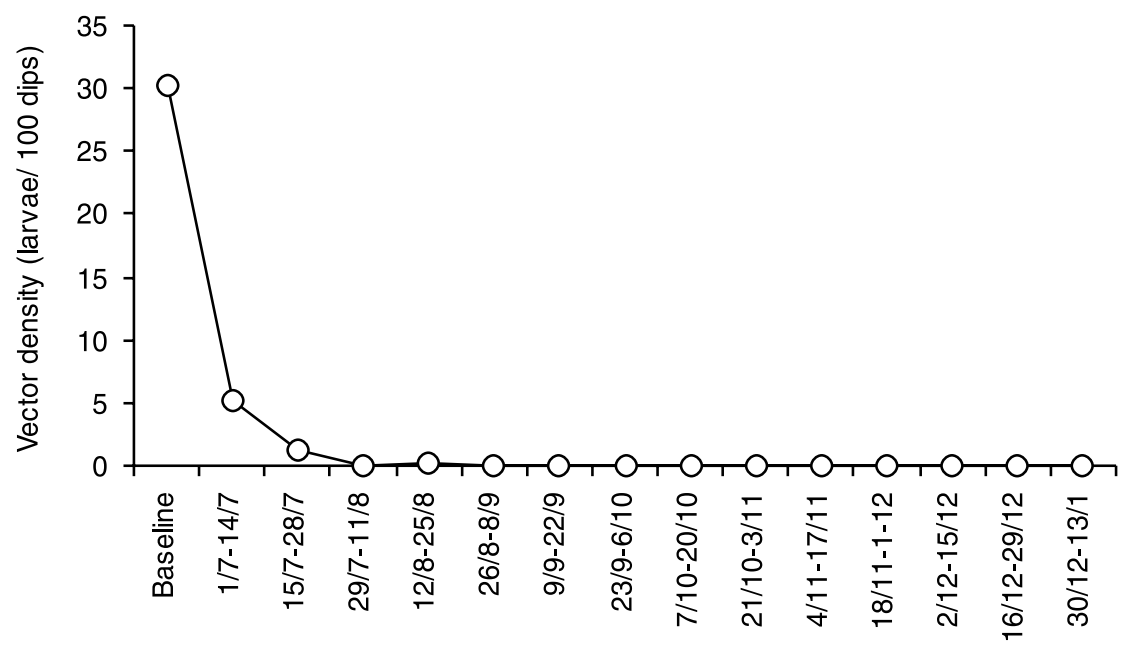

Fortnightly periods

Figure 2 Vector density at intervention sector using half-dose weekly larvicide (June to December 2001)

المجلة الصحية لشرق المتوسط، منظمة الصحة العالمية، المجلد التاسع، العدد ع، بr.ب 


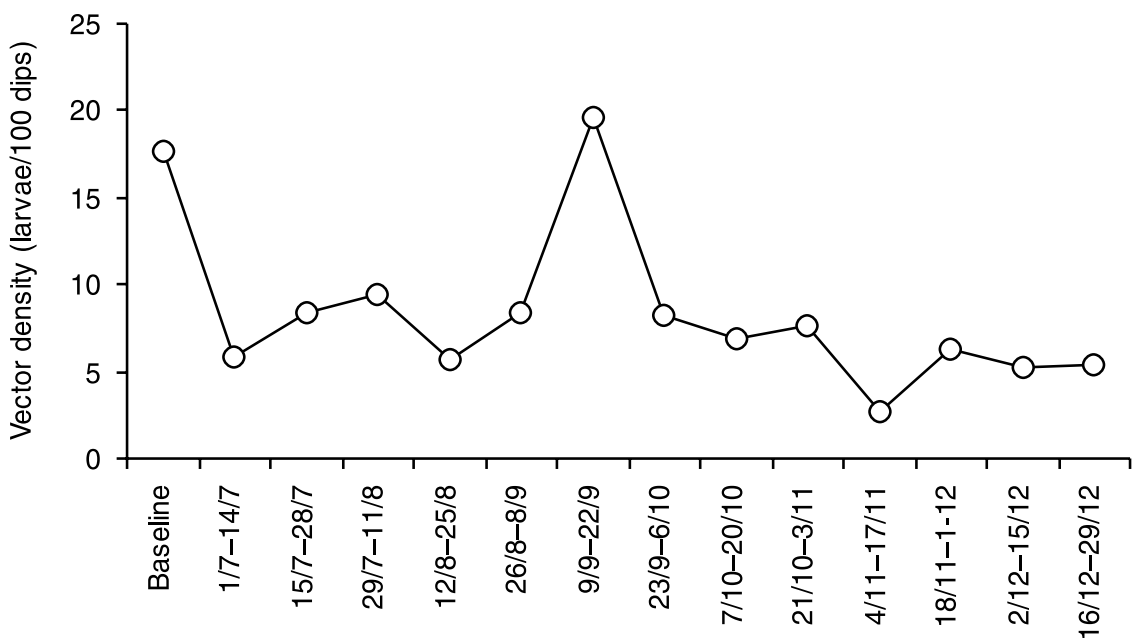

Fortnightly periods

Figure 3 Vector density at intervention sector using full-dose fortnightly larvicide (June to December 2001)

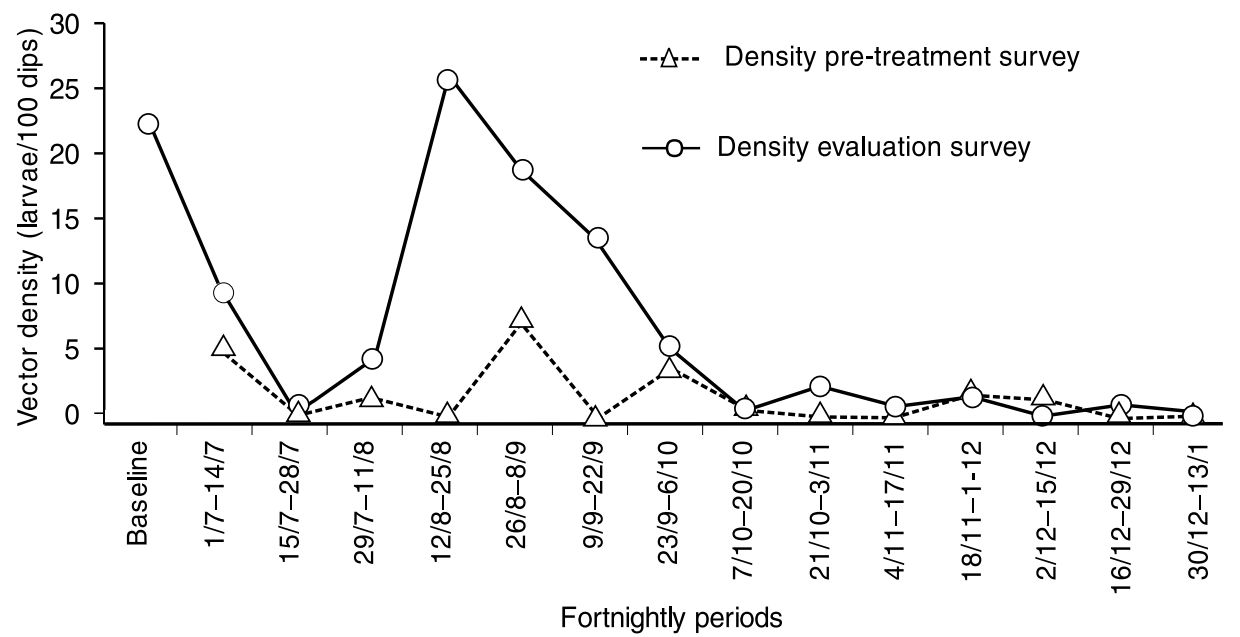

Figure 4 Vector density at intervention sector treating only positive sites (June to December 2001)

المجلة الصحية لشرق المتوسط، منظمة الصحة العالمية، المجلد التاسع، العدد ؟، ب... 
decreased after only 2 cycles from the start of the study from 30 larvae/100 dips to zero and remained at zero throughout the study period (Figure 2). However, in the sector treated with full-dose temephos fortnightly the larva density fell initially then rose to levels that fluctuated from 520 larvae/100 dips (Figure 3). This method controlled larval multiplication by nearly $50 \%$ in the peak season; however, the method was more effective in the cooler season (October to December) than the hot season. The strategy of larva surveying and treating only larva-positive sites was more effective than the fortnightly overall treatment. Once the system was in place, good control of vector breeding was achieved. However, in the peak breeding period (August to September), control was not more than $50 \%$ (Figure 4 ).

The susceptibility tests showed that, when exposed to $0.125 \mathrm{mg} / \mathrm{L}$ temephos, An. culicifacies larvae recorded $100 \%$ mortality pre-intervention and during the intervention periods, while An. stephensi larvae recorded mortality between $94 \%$ and $97 \%$ throughout the study period.
The odds ratios for the 3 strategies showed they were significantly more effective compared with the control strategy (Table 2). Table 2 also shows the attributable risk fraction. It is clear that the 'halfdose weekly' strategy had more effect than other strategies on decreasing larvae breeding.

The costs of the 3 strategies and the cost-benefit ratios are given in Table 3. Temephos 50\% EC costs about US\$ 20 per litre. The $10 \mathrm{~L}$ pump used covers a $1000 \mathrm{~m}^{2}$ area. Thus for achieving the normal dose of $1 \mathrm{ppm}$ currently in use in the Oman national malaria eradication programme, $20 \mathrm{~mL}$ of $50 \%$ temephos (10 mL active ingredient) was added to $10 \mathrm{~L}$ of water to cover 1000 $\mathrm{m}^{2}$ sprayable surface area. Wages for labourers were approximately US\$ 13 per day. In the usual programme, 1 sector would cost on average US\$ 1884 for the same period (1 ppm dose) over 27 cycles. In our trial period, the cost was US\$ 971 for the full-dose fortnightly cycle, US\$ 1792 for the half-dose weekly cycle and US\$ 5572 and for treating only positive sites (Table 3). Thus in the fortnightly

Table 2 Positive predictors of presence of anopheline breeding places: comparison of geographical variables and 3 different larviciding strategies

\begin{tabular}{lccrc}
\hline Predictors & OR & P-value & 95\% Cl & $\begin{array}{c}\text { Attributable } \\
\text { risk fraction }\end{array}$ \\
\hline Temperature & 1.03 & 0.38 & $0.96-1.10$ & 0.03 \\
$\mathrm{pH}$ & 1.84 & 0.39 & $0.45-7.46$ & 0.45 \\
Full-dose fortnightly & 0.08 & $<0.001$ & $0.04-0.14$ & -12.3 \\
Half-dose weekly & 0.008 & $<0.001$ & $0-0.14$ & -124.0 \\
Treat only if positive & 0.03 & $<0.001$ & $0.015-0.05$ & -32.3 \\
\hline
\end{tabular}

OR $=$ odds ratio.

$\mathrm{Cl}=$ confidence intervals

المجلة الصحية لشرق المتوسط، منظمة الصحة العالمية، المجلد التاسع، العدد ع، ب... 
strategy, US\$ 80.9 was spent to reduce larvae breeding by $1 \%$, compared with US\$ 174.0 in the 'treat only if positive' strategy and US\$ 17.9 in the half-dose weekly cycle to achieve the same unit of larvae breeding reduction.

\section{Discussion}

Susceptibility monitoring during the pre-intervention period [6] suggested that a temephos concentration of $0.125 \mathrm{mg} / \mathrm{L}$ was sufficient to achieve $100 \%$ mortality for An. culicifacies and more than 93\% for An. stephensi, rather than the $0.250 \mathrm{mg} / \mathrm{L}$ dose proposed by WHO for most anophelines [7]. The same results were recorded from the study area during pre- and post-intervention observations.

There was evidence that certain breeding sites were favourites for vector breeding. It was clearly observed that $58 \%$ of control sector breeding sites and $49 \%$ of 'treat only if positive' sites showed larvae present on 2-10 occasions when they were surveyed, indicating an attraction for the vectors and tendency to go to the same sites repeatedly for egg laying.

Vector breeding in the control sector was 20-50 larvae/100 dips during the study period with a peak after September. Halfdose temephos applied weekly showed an almost immediate drop in vector larvae density, which was maintained throughout the study period. Full-dose temephos applied fortnightly controlled larval multiplication by only $50 \%$ in the peak season, although this strategy was more effective in the cooler season (October to December) than the hot season. Our findings confirm the observation that temephos is not a good residual larvicide and we can therefore conclude that a dose of 1 ppm, if applied infrequently, does not have any

المجلة الصحية لشرق المتوسط، منظمة الصحة العالمية، المجلد التاسع، العدد ع، ب..ب 
advantage over 0.5 ppm applied more regularly.

A strategy of larval surveying and treating only larva-positive sites appears to be more promising than fortnightly overall treatment. Ultimately good control of vector breeding was achieved. However, in the peak breeding period (August to September) control was not more than $50 \%$. Although the effect was not statistically significant, temperature again seemed to help control breeding in the cooler periods, when the aquatic stage of development slows. In the control sector during the same period, larval density was higher, which was perhaps due to the accumulation of 2-3 broods (i.e. a high proportion of early stage larvae).

The fortnightly cycle was the most economical overall, but the least effective during the peak breeding season. However, during the cooler season, when the breeding cycle is prolonged, this schedule was effective.

The cost-benefit analysis (expressed in terms of each percentage reduction of larvae breeding) showed US\$ 80.9 was spent in the full-dose fortnightly strategy to reduce larvae breeding by $1 \%$ compared with only US\$ 17.9 in the half-dose weekly cycle to achieve the same reduction in larvae breeding. Monitoring and treating only positive sites was much more expensive because of the higher labour and transport costs: US\$ 174.0 to reduce larvae breeding by $1 \%$.

The fact that the weekly application of half-dose temephos yielded far better results than fortnightly application of the full dose illustrates a number of points. Firstly, there is a need for weekly application of larvicide, since the local climatic conditions ensure a relatively short breeding cycle of An. culicifacies and An. stephensi. Secondly, the sensitivity of the local anopheline vector larvae to temephos was high. Thirdly, the fortnightly application of temephos had a relatively short-lasting effect. This latter point is to be expected under the prevailing climatic conditions.

There is little difference in the environmental impact of the weekly half dose or fortnightly full dose of temephos schedules. From the point of view of increasing the selection pressure for resistance the fortnightly application of temephos $1 \mathrm{ppm}$ has to be regarded as slightly more risky than weekly application of $0.5 \mathrm{ppm}$ since it regularly permits a recovery of breeding during the intervals between the temephos applications. The strategy of larval survey and treatment of only positive sites reduced the use of larvicide by $95 \%$ and is thus environmentally the most acceptable method since negligible amount of larvicide were used. However, larviciding of positive breeding sites proved to be the least effective method during the peak breeding season. It was also the most expensive method as labour and transport costs were much higher than other approaches.

\section{Conclusions}

It can be inferred from the study results that using half the normal dose of larvicide is sufficient to control Anopheles spp. breeding and is in fact more effective than the usual dose, if it is used on a weekly cycle. It has the advantage of a saving in cost and is environmentally comparatively safer than the usual method. Further studies could investigate the strategy of using weekly half-dose larvicide only in the breeding season and fortnightly half-dose in cooler conditions. Unfortunately, the environmentally favourable method of selective treatment of positive sites was the least effective and most expensive strategy;

المجلة الصحية لشرق المتوسط، منظمة الصحة العالمية، المجلد التاسع، العدد ؟، ب..r 
however, a modified method could make it more economical, e.g. using a mobile team to treat several sectors.

\section{Acknowledgements}

This investigation received technical and financial support from the joint WHO East- ern Mediterranean Region (EMRO), Division of Communicable Diseases (DCD) and the WHO Special Programme for Research and Training in Tropical Diseases (TDR): the EMRO/DCD/TDR Small Grants Scheme for Operational Research in Tropical and Communicable Diseases.

\section{References}

1. Promoting rational use of drugs and correct case management in basic health services. The prescriber, no. 18. New York, UNICEF/World Health Organization, 2000.

2. Roll back malaria: increasing the momentum. Geneva, World Health Organization. 1999. Electronic access: http:// mosquito.who.int/docs/advocacy/ Mom(en).pdf (Last accessed 12 June 2004.)

3. Emilio P. A textbook of malaria eradication. Oxford, Oxford University Press, 1969.

4. Insecticide resistance and vector control: thirteenth report of the WHO Expert Committee on Insecticides. Geneva, World
Health Organization, 1963 (WHO Technical Report Series, No. 265).

5. Parvez SD. Anophelines of the Sultanate of Oman. Muscat, Directorate of Environmental Health and Malaria Eradication, 1995 (SD/Doc/12).

6. Parvez SD. Vector susceptible status to various pesticides in the Sultanate of Oman. Muscat, Directorate of Environmental Health and Malaria Eradication, 1994 (SD/Doc/8).

7. Resistance of vectors and reservoirs of disease to pesticides. Tenth report of the WHO Expert Committee on Vector Biology and Control. Geneva, World Health Organization, 1986 (WHO Technical Report Series, No. 737). 